\title{
SOCIOLINGUÍSTICA APLICADA AO ENSINO DE LÍNGUA PORTUGUESA: ANÁLISE DAS CORRELAÇÕES ENTRE AS CONCEPÇÕES DO PROFESSOR E O LIVRO DIDÁTICO ${ }^{1}$
}

\author{
LÚCIO CESAR OLIVEIRA SILVA ${ }^{1}$ \\ FÁBIO FERNANDES TORRES ${ }^{1}$ \\ ${ }^{1}$ Universidade da Integração Internacional da Lusofonia Afro-Brasileira - UNILAB \\ <lucio-cesar@hotmail.com><fabioftorres@unilab.edu.br>
}

DOI: $10.21439 /$ conexoes.v12i2.1443

\begin{abstract}
Resumo. Este artigo tem o objetivo de analisar o tratamento dado à variação linguística pelo livro didático da coleção Português: Linguagens (CEREJA; MAGALHãES, 2013), volume 2, e, pelos professores que o utilizam, a partir de suas concepções, coletadas por meio de questionários, no contexto de uma escola pública de Ensino Médio de Redenção-CE. Partimos do pressuposto de que tanto o livro didático, como os professores consultados, abordam a variação linguística de forma insuficiente, tratando-a apenas como questão de linguagem formal e informal, sem proporcionar a reflexão necessária acerca dos fenômenos em variação que ocorrem no português brasileiro. Para tanto, amparamos nossa pesquisa nas reflexões de Bagno (2007), Bortoni-Ricardo (2004), Antunes (2003), dentre outros, discutindo as correlações entre o livro didático, o professor e o ensino. Os resultados indicam que tanto os professores, como o livro didático, apresentam informações superficiais e imprecisas quanto ao tratamento da variação linguística no Ensino Médio.
\end{abstract}

Palavras-chaves: Sociolinguística. variação. ensino.

Abstract. This paper aims to analyze the attention given to linguistic variation in the collection textbook Português: Linguagens (CEREJA; MAGALHãES, 2013) volume 2, and the conception of teachers who use it in one of the high schools of the municipality of Redenção, Ceará state, Brazil. The paper assumes that both the textbook and teachers insufficiently address the phenomenon of linguistic variation, endorsing it only as an issue of formal and informal language, lacking providing a necessary reflection about the variation occurring in Brazilian Portuguese. Therefore, this research is based on Bagno (2007), Bortoni-Ricardo (2004), Antunes (2003), among others, arguing the correlations between the textbook, the teacher and the teaching. Results indicate that both teachers and textbook present superficial and inaccurate information concerning to linguistic variation.

Keywords: Sociolinguistics. variation. education.

\section{INTRODUÇÃO}

Considerando que a padronização linguística é impositiva e que, independentemente do regime político, está presente em todos os estados modernos (BORTONIRICARDO 2005, p. 14), no Brasil, desde a década de

\footnotetext{
${ }^{1}$ As discussões apresentadas aqui estão desenvolvidas no Trabalho de Conclusão de Curso, intitulado Sociolinguística, variação e
}

60, quando do início do processo de democratização do ensino público, há um esforço contínuo por parte dos linguistas para que as diversas variedades da língua portuguesa sejam consideradas como formas legítimas em

ensino: correlações entre as concepções do professor e o livro didático, de Lúcio Cesar Oliveira Silva, orientado pelo Prof. Dr. Fábio Fernandes Torres. 
relação à variedade dita "padrão". Esse esforço ganhou notoriedade com a implementação dos Parâmetros Curriculares Nacionais, em 1997.

Diante de uma realidade tão heterogênea como a que a sociedade brasileira está inserida, não é concebível que essas diferenças sejam ignoradas pela escola, e que esta imponha uma variedade a outra, reproduzindo preconceitos velados ou camuflados aos alunos que falam as variedades estigmatizadas. Por compreender que a variação existe em todas as línguas naturais humanas, a abordagem da variação linguística pode contribuir satisfatoriamente no combate ao preconceito linguístico, corroborando a necessidade de a escolar excluir conceitos de certo e errado, sem, contudo, desprezar o acesso às variantes de prestígio.

Cientes da importância que o livro didático alcançou em sala de aula, como o principal recurso didático, pretendemos, neste artigo, averiguar como o livro utilizado em uma das escolas estaduais de Redenção-CE aborda o fenômeno da variação linguística, bem como o conhecimento que os professores de Língua Portuguesa que atuam na escola pesquisada possuem. Para tanto, recorreremos às contribuições da Sociolinguística para analisarmos os dados provenientes dos questionários aplicados a professores e do exame das seções de produção textual e conhecimentos linguísticos do livro didático.

Após a introdução, este artigo está divido em três partes: inicialmente, revisitaremos alguns conceitos teóricos da sociolinguística variacionista; em seguida, passaremos à análise dos dados em duas seções: a que trata do livro didático, norteada por três perguntas, seguindo-se a análise do questionário aplicado aos professores. Por fim, retomaremos, nas conclusões, como a variação linguística é concebida no livro em análise e pelos professores que o utilizam.

\subsection{DO ESTRUTURALISMO SASSUREANO À SO- CIOLINGUÍSTICA VARIACIONISTA}

É inegável a contribuição do linguista Ferdinand de Saussure para a linguística modernaa. Para além da visão estruturalista, Carvalho (1987) afirma que o grande mérito do trabalho de Saussure foi trazer ordem aos estudos linguísticos, delimitando o objeto de estudo da nova ciência e definindo uma metalinguagem padrão que pudesse ser utilizada universalmente.

Calvet (2002, p. 12) afirma que o Estruturalismo recusou o caráter social da língua, privilegiando a estrutura abstrata, em detrimento das influências do meio social. Os pesquisadores sociolinguistas fizeram dessa lacuna do Estruturalismo um campo fértil de estudos. Discordando da concepção de Saussure, Labov
(2008[1972]) postula que a língua é heterogênea, diversificada, variável e passível de influências de fatores linguísticos e extralinguísticos, como idade, gênero, escolaridade, renda, dentre outros. Nascia, dessa forma, a Teoria da Variação e Mudança Linguística, advinda da própria Sociolinguística, que se debruça sobre o estudo da relação entre a língua em uso e a sociedade.

Conforme Alkmim (2012), o diferencial da Sociolinguística é o foco dado à língua, em seus mais variados contextos. Não há uma preocupação em estudar a língua idealizada em compêndios, mas em situações reais de uso. Todas as variedades linguísticas, de igual modo, possuem regras pontuais, condicionada por fatores que podem ser sistematizados pormenorizadamente.

\subsection{A sociolinguística aplicada ao ensino}

Para a Sociolinguística, não há um uso melhor ou pior que outro. Ocorre que há variações em todas as línguas naturais, tanto em níveis fonéticos, fonológicos ou semânticos. No caso do Brasil, a Língua Portuguesa não está isenta de variação e de mudanças, embora alguns continuem insistindo em propagar um "purismo linguístico".

Urge, diante disso, uma nova postura do professor quanto à implementação de um ensino que não exclua a língua que o estudante já traz de sua casa, mas propicie ao aluno a reflexão sobre o seu próprio uso da língua, sem discriminá-lo, com o fim de levá-lo a ampliar o seu próprio repertório linguístico. Neste caso, o foco deixa de ser mudar o dialeto do aluno e sim torná-lo competente para fazer usos adequados, visto que a competência comunicativa o tornará capaz de monitorar seu próprio estilo linguístico, adequando-o, quando necessário (BORTONI-RICARDO, 2004, p. 73).

Como implementar, na prática, um ensino que priorize uma reeducação sociolinguística? Bortoni-Ricardo (2004) insiste que, em primeiro lugar, deve-se definir uma agenda de desenvolvimento de competências que capacite o aluno a circular em todos os espaços sociolinguísticos, com eficácia, partindo sempre do que o aluno já traz consigo, como afirma Antunes (2003). Assim, é essencial que o professor seja reorientado, reeducado sociolinguisticamente, visto que é peça fundamental na condução de uma educação produtiva e não excludente.

\section{METODOLOGIA}

O universo de pesquisa divide-se em dois corpora: o primeiro trata-se do volume 2 pertencente à coleção Português: linguagens (CEREJA; MAGALHãES. 
2013). O segundo trata-se de um questionário aplicado a professores que utilizam o livro didático no Ensino Médio, em uma escola da rede estadual em RedençãoCE.

O livro em análise é constituído de quatro unidades subdivididas em seções de literatura, análise linguística, produção textual e interpretação textual. Dentre elas, selecionamos recortes das seções "língua: uso e reflexão" e "produção textual" para análise.

O questionárid ${ }^{2}$ baseado em Raquel (2007), trouxe perguntas a respeito do livro didático, da formação do professor e dos conhecimentos sociolinguísticos. Foi aplicado na forma de entrevistas gravadas, individualmente, com três professores que utilizam o volume $2 \mathrm{da}$ coleção no $2^{\circ}$ ano do Ensino Médio.

\section{RESULTADOS E DISCUSSÕES}

Analisaremos, neste trabalho, o volume 2 da coleção Português: Linguagens (CEREJA; MAGALHãES 2013), utilizado em uma das escolas da rede estadual de ensino no município de Redenção-CE, onde realizamos nossa pesquisa. Optamos por este volume pelo seguinte motivo: é o livro adotado pela escola e utilizado pelos professores entrevistados nesta pesquisa, o que torna possível verificar as correlações entre as concepções do professor de Língua Portuguesa e livro didático, a respeito de variação linguística. O corpus de análise compreende as seções intituladas de "produção textual", e "língua: uso e reflexão", para seção de conhecimentos linguísticos.

A seção de produção textual organiza-se seguindo a ordem: apresentação do gênero, exercícios, planejamento, produção e revisão. Semelhantemente, a seção "língua: uso e reflexão" organiza-se nas subseções: construindo o conceito, conceituando, semântica e discurso e exercícios. Observaremos, no presente trabalho, se a abordagem da variação linguística se faz presente no livro didático, de forma clara, coerente com as teorias sociolinguísticas.

\footnotetext{
${ }^{2}$ No questionário, fizemos as seguintes questões: Que critérios você utiliza quando vai adotar o livro didático? O livro didático ajuda na sua prática? Como? Você acha que os objetivos do ensino de LP no ensino médio estão contemplados no livro didático? O que caracteriza a fala dos alunos? O que você pensa deste modo de falar? Como você caracterizaria o povo cearense? O que você pensa sobre o modo de falar dos cearenses? Você trabalha com textos de diferentes níveis de formalidades? Por quê? Você trabalha com textos de diferentes dialetos? Por quê? Como você aborda a gramática em sala de aula? Você trabalha com as noções de certo e errado em sala de aula? Por quê? Como você explica a seus alunos a diferença entre a fala dos mais velhos e o modo de falar dos jovens? Como os alunos encaram a fala dos professores?
}

As duas seções em estudo possuem exaustivas listas de exercícios, perfazendo um total de 89. Para fins de análise, empreenderemos recortes de cada seção, entre notas explicativas e exercícios. Elegemos, nesta empreitada, três categorias que servirão de bases para nossa análise: a variação linguística, a análise linguística e o emprego adequado de conceitos. Na sequência, procederemos às análises.

a) O livro didático aborda a variação linguística e/ou fenômenos variáveis do Português?

Verificamos que há, no livro, uma sinalização quanto à intenção de realizar um trabalho menos tradicional, voltado para a análise linguística, com reflexão sobre o funcionamento da língua, e, sobretudo, contemplando a variação linguística em seus mais variados níveis. Porém, nas unidades e capítulos de conhecimentos linguísticos e produção textual, a intenção inicial não se desenvolve com eficácia no que tange à abordagem da variação linguística. Vejamos alguns exemplos.

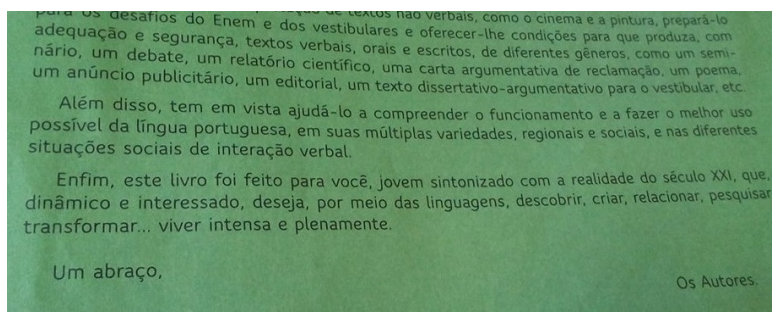

Figura 1: Exemplo 1. Fonte: Cereja e Magalhães (2013 p. 3).

De início, na apresentação (p.3), ao explicar a proposta de trabalho que o livro Linguagens dará a língua portuguesa, há uma breve referência à abordagem da variação linguística:

\footnotetext{
Além disso, tem em vista ajudá-lo a compreender o funcionamento e a fazer o melhor uso possível da língua portuguesa, em suas múltiplas variedades, regionais e sociais, e nas diferentes situações sociais de interação verbal." (CEREJA; MAGALHãES. 2013, p. 3)
}

Os autores citam, nesse trecho, que há "múltiplas variedades" na língua portuguesa, enfatizando que a opção de língua como estrutura heterogênea e variável norteará o tratamento dado ao português, no livro didático, embora citem apenas dois níveis de variação (regionais e sociais). Bagno (2007, p. 120) esclarece que: "Um dos principais problemas que encontramos nos livros didáticos é uma tendência a tratar da variação linguística em geral como sinônimos de variedades regionais, rurais ou de pessoas não escolarizadas". Neste sentido, o termo "regionais", empregado pelos autores, 
necessita de melhor esclarecimento, com vistas a não deixar dúvidas quanto ao que se quer informar ao estudante.

Observamos que, nesse mesmo fragmento, os autores já poderiam ampliar a apresentação da variação linguística, informando os outros níveis de variação, relacionadas à estratificação social, como: sexo, idade, condição social, além das mudanças e transformações que ocorrem com o passar do tempo (variação diacrônica). Isso deixaria a apresentação mais consistente.

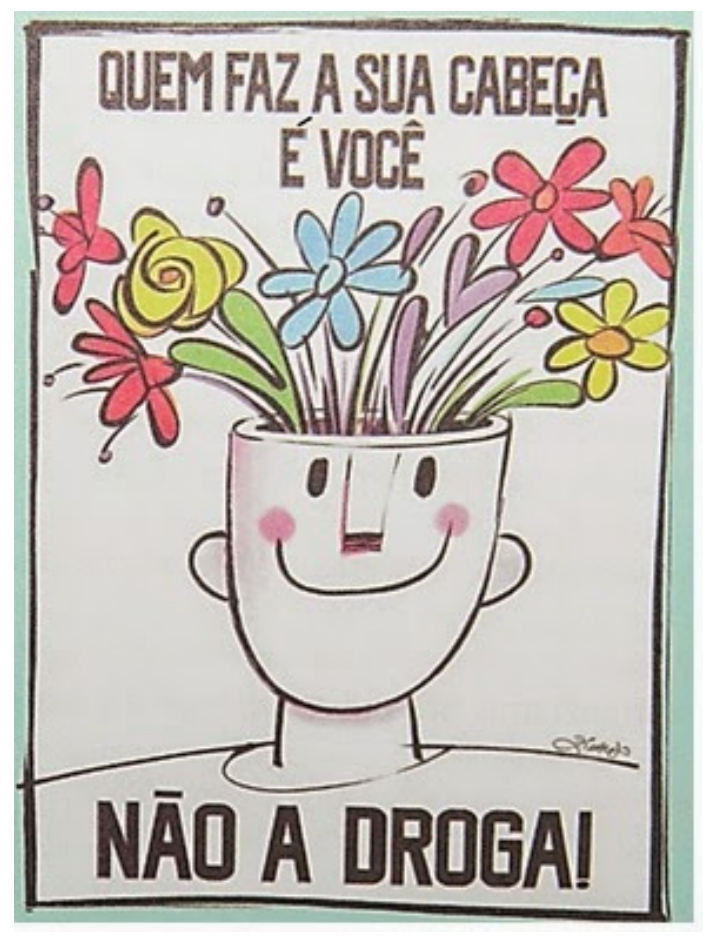

$$
\begin{gathered}
\text { Figura 2: Exemplo } 2 . \\
\text { Fonte: Cereja e Magalhães } 2013 \text { p. 22). }
\end{gathered}
$$

Ao trabalhar gêneros publicitários, na seção de produção de texto Cereja e Magalhães (2013, p. 22-23), após questionar o leitor sobre a finalidade e público destinatário do cartaz, os autores perguntam: "Que variedade linguística foi empregada no texto?’”

Pontuamos aqui uma incoerência didática. Como o estudante poderá responder a esse questionamento sem antes os autores terem trabalhado o conceito de variação linguística? Ficará, unicamente, sob a responsabilidade do professor? Se o professor não fizer uso das teorias sociolinguísticas, em sua prática, o estudante será capaz de responder coerentemente à questão?

De acordo com a resposta esperada no Manual do Professor, espera-se que o estudante responda que, no cartaz, há o uso de uma linguagem informal, visto que utiliza uma gíria usual da informalidade, em conversas. Ressalte-se que, mesmo na resposta indicada pelo manual, não há um direcionamento ao professor para que aborde, com clareza, as questões de variação da língua, ficando unicamente a critério do professor em abordar ou não.

b) Os conhecimentos linguísticos são ensinados com dados reais de uso? São abordados de forma adequada?

No que tange à análise linguística, verificamos importantes avanços, como a utilização de tirinhas, notícias de jornais, cartazes, placas informativas, porém, com abordagens ainda insatisfatórias. Como mencionamos, na seção anterior, que não é suficiente a utilização de dados de usos reais, se não forem trabalhados, de forma coerente, com uma perspectiva pautada na reflexão sobre o uso linguístico, essa constatação também é válida nesta seção. De modo semelhante, os autores não abrem espaço para tratar de forma clara a existência de variedades linguísticas e preconceito linguístico.

Constatamos que, em grande parte das seções analisadas, há resquícios do método tradicional de ensino, muito embora percebamos mudanças no que diz respeito ao excesso de exercícios de ordem metalinguística. Exemplificaremos, a seguir, alguns tipos de exercícios que ainda se repetem no livro e merecem reformulações:

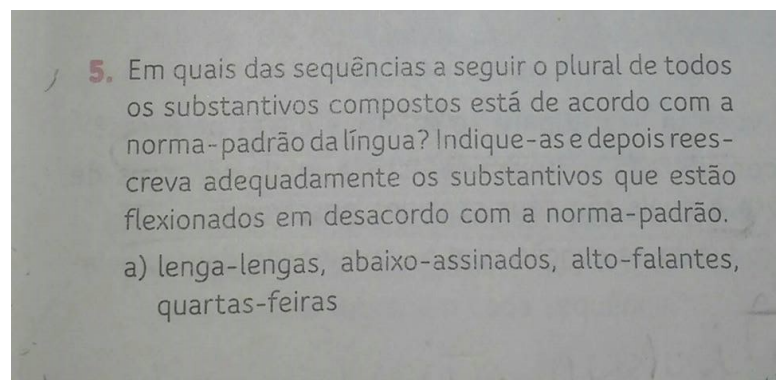

Figura 3: Exemplo 3. Fonte:Cereja e Magalhães (2013 p. 33).

Nesse item, os autores solicitam que o aluno indique e reescreva a lista de opções em que os substantivos estão em desacordo com a norma-padrão. Com relação a esse tipo de exercícios, Bagno (2007, p. 123) afirma que atividades que orientam a reescrita de variedades em desacordo com a norma culta são preconceituosas, pois transmitem a ideia de que há somente uma única variedade válida: a norma culta. Muito pior, o exemplo pede que o aluno reescreva em acordo com a "norma-padrão", que, aliás, não é uma variedade autêntica de uso, mas idealizada em compêndios normativos (BAGNO, 2011, p. 984). 
Como já mencionamos, não se trata de privar o aluno do conhecimento das variedades de prestígio, ou de substituir uma variedade por outra. A respeito disso, Bortoni-Ricardo (2005, p. 26) orienta que:

A aprendizagem da norma culta deve significar uma ampliação da competência linguística e comunicativa do aluno, que deverá aprender a empregar uma variedade ou outra, de acordo com as circunstâncias da situação de fala.

Com base neste princípio, ao invés de pedirem a reformulação dos substantivos, os autores poderiam exemplificar contextos reais de usos e trabalhar com o aluno a adequação das palavras ao contexto e não à "norma-padrão". Verificamos, portanto, que a seção de conhecimentos linguísticos ainda segue uma abordagem tradicional de gramática, embora com algumas inovações. Vejamos outros exemplos da mesma seção.

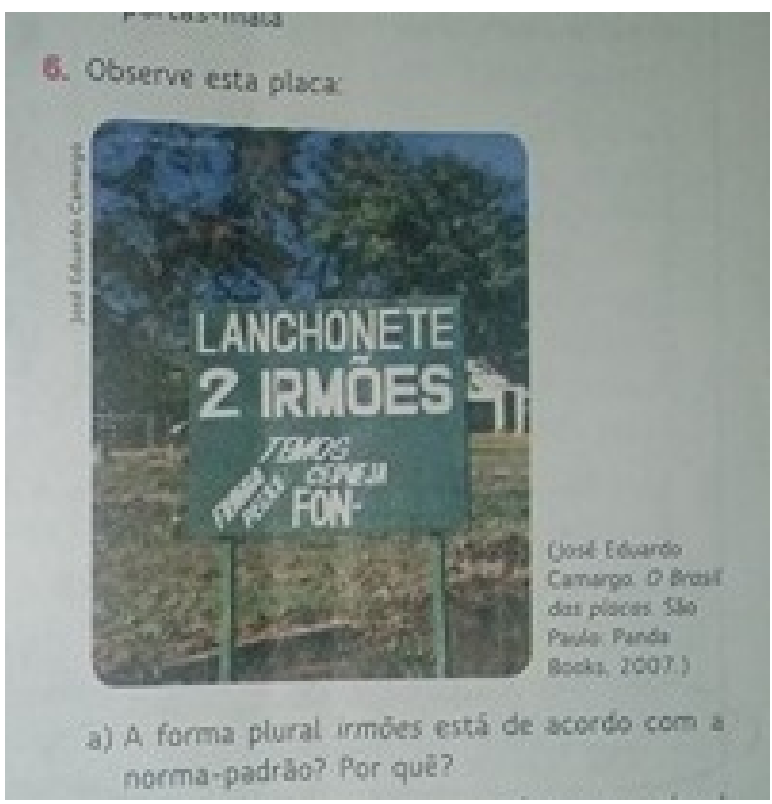

Figura 4: Exemplo 4

Fonte: Cereja e Magalhães (2013 p. 33).

No exemplo 4, verificamos que os autores utilizam uma placa comercial de uso real como exemplo. Porém, ao perguntar se a forma plural "irmões" está em acordo com a norma-padrão, o foco volta-se, novamente, para uma abordagem ainda muito tradicional, sem contemplar a realidade da variante empregada no anúncio. $\mathrm{O}$ exercício novamente testa o conhecimento do aluno quanto à norma-padrão empregada. Seria mais produtivo insistir que essas construções não são erros, mas possibilidades, ou mesmo tentar entender a lógica linguística empregada. c) O livro confunde a norma-padrão com uma variedade real da língua? Ou norma-padrão com norma culta?

Antes de empreendermos esta análise, precisamos buscar o entendimento do que na verdade é a normapadrão. Consideremos, então, a afirmativa de Bagno (2007, p. 106):

\footnotetext{
A norma-padrão não faz parte da língua, não corresponde a nenhum uso real da língua, constituindo-se muito mais como um modelo, uma entidade abstrata, um discurso sobre a língua, uma ideologia linguística [...]."
}

Com base na afirmativa, compreendemos que não há, no português brasileiro, falantes autênticos da norma-padrão, por ser um modelo abstrato, uma ideologia. Até mesmo os falantes chamados "cultos" fazem usos considerados "errados" pela gramática normativa, isso porque a língua muda, transforma-se com o passar do tempo. Por exemplo, ninguém utiliza mais construções como: "dar-te-ei o livro amanhã". Na verdade, o que existe são falantes da norma-culta ou das variedades mais prestigiadas. "Por norma culta, compreendemse as variedades de usos reais, com falantes reais, que caracterizam a fala e a escrita dos cidadãos moradores de áreas urbanas" (BAGNO, 2007, p. 130). Ainda sobre isso, Faraco (2008) esclarece que o termo norma culta faz referência à variedade utilizada pelas pessoas que possuem mais contato com a cultura escrita e fazem usos mais aproximados das normas.

Destacamos que o volume em análise não apresenta quaisquer conceitos ou discussão sobre o que é normapadrão ou norma culta.

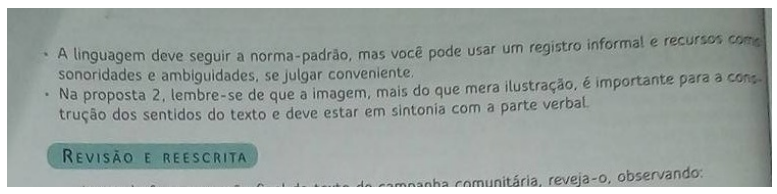

Figura 5: Exemplo 5. Fonte: Cereja e Magalhães (2013 p. 60).

Verificamos, no exemplo, que os autores confundem claramente a "norma- padrão" com a "norma culta". Como dito ao início, por ser um padrão idealizado, não há falantes reais da norma-padrão, sequer os escritores consagrados dos séculos passados. Ressalte-se que, se os alunos devem "seguir" a norma-padrão, não há espaço para utilizarem um registro informal (como os autores orientam); constata-se, dessa forma, mais um equívoco no comando.

Nesse trecho, os autores apresentam uma inovação positiva, abrindo a possibilidade para o aluno utilizar 


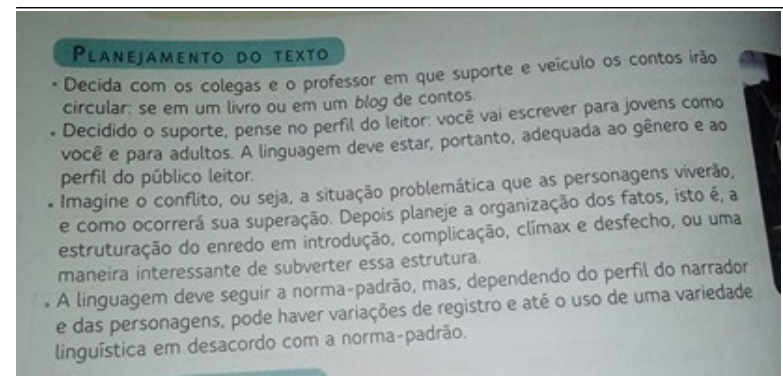

Figura 6: Exemplo 6 Fonte: Cereja e Magalhães (2013 p. 78)

(caso necessário) um registro de variedade em desacordo com a norma-padrão. Não podemos negar que os autores estão bem intencionados quanto ao comando da produção, contudo, a utilização de termos imprecisos coopera de forma significativa para perpetuar o engano de que escrevemos obedecendo aos ditames de compêndios das gramáticas normativas.

Ressaltamos que as 11 seções de produção textual giram em torno de comandos semelhantes, nos quais sempre há um direcionamento para a utilização da norma-padrão, com mais ou menos formalidade, dependendo do contexto. No entanto, não há conceituação dos termos empregados nos comandos das produções.

\subsection{A percepção de professores de língua portu- guesa acerca da variação}

Os dados analisados nesta parte da pesquisa provêm de um questionário com perguntas a respeito do livro didático, da formação do professor e dos conhecimentos sociolinguísticos. Foi aplicado na forma de entrevistas gravadas, individualmente, com os três professores que utilizam o volume 2 da coleção Português: Linguagens (CEREJA; MAGALHãES, 2013). Dentre as 15 perguntas presentes no questionário, selecionamos as mais significativas, com o objetivo principal de verificar a percepção do professor quanto à abordagem da variação linguística. A Tabela 1 apresenta informações referentes aos professores entrevistados e aos dados coletados sobre a formação continuada dos professores. $\mathrm{Na}$ sequência, analisaremos com mais detalhes as respostas obtidas através do questionário.

a) De que cursos de capacitação você participou? Estes cursos direcionaram mudanças na sua prática pedagógica? Quais?

Nossos objetivos com essas questões são dois: verificar o impacto das capacitações na prática dos professores e se, de alguma forma, as teorias da Sociolinguística eram contempladas nestas capacitações.
Com relação às capacitações, os três professores mencionaram que o último curso ofertado pela Secretaria de Educação do Estado foi o "Pacto pelo Ensino Médio”, em 2014. De igual modo, informaram que já participaram de outros cursos de aperfeiçoamento realizados por entidades, como a UFC, UECE e UNILAB. Entretanto, de acordo com o depoimento dos professores, há ausência de capacitações regulares direcionadas aos professores do ensino médio (ver Tabela 01).

Todos os professores entrevistados concordaram que os cursos de que participaram influenciaram suas práticas pedagógicas, embora, muitas vezes, sejam imprecisos em exemplificar essas influências. Vejamos, como exemplo, o que diz o professor (A):

Professor (A):

"Recentemente, assim... o mais recente foi... o Pacto
pelo Ensino Médio (...) e o pacto, ele, exatamente, trazia
algumas mudanças na prática pedagógica, a gente com-
partilhava com os outros colegas e isso acaba influenci-
ando, realmente, as nossas atitudes porque traz pra gente
o reflexo do novo e agente tem que se adaptar a esse
novo(...) mas...assim, mais recente do que esse, ultima-
mente, realmente, eu não participei de outros cursos de
capacitação.

Embora nesse tópico o professor (A) não tenha citado conhecimentos sociolinguísticos, a fala indica, com algumas imprecisões, que as capacitações e/ou cursos de aperfeiçoamento tendem a ter impactos positivos em suas práticas pedagógicas, visto serem a oportunidade de apropriarem-se de novas teorias.

b) Como você avalia o livro didático? Você participou da escolha do livro de LP? Como foi o processo de escolha?

Nesse tópico, percebemos certa unidade nas respostas. Os professores (A) e (C) informaram que o livro "é bom" e que estão satisfeitos com todos os volumes da coleção, contudo não citaram exemplos consistentes a respeito de como o livro apresenta os conteúdos, detendo-se apenas a questões de organização estrutural. Não percebemos, aqui, nenhuma resposta que contemplasse de maneira eficaz as teorias sociolinguísticas, embora, um dos professores tenha comentado o seguinte:

Professor (B):

[...] a minha percepção sobre o livro didático é que... os nossos livros eles não têm um total conteúdo que esteja direcionado a, por exemplo, a ao nordeste, a nossa linguagem aqui, então, é, é (...) ele é um livro bom porque contempla a norma- padrão, no quesito, no, na,na, no básico, né? Da, no estudo da língua. Mas quando trata-se de questões mais regionalistas, que traga mais pra realidade do nosso aluno, fica um pouco a desejar. 
Quadro 1: Formação dos professores.

\begin{tabular}{|c|c|c|c|}
\hline Questões & Professor (A) & Professor ( B ) & Professor ( C ) \\
\hline Tempo de magistério & 19 anos & 13 anos & 13 anos \\
Nível de formação & Especialista & Especialista & Graduado \\
Última capacitação & Há 2 anos & Há 3 anos & Há 3 anos \\
\hline
\end{tabular}

Fonte: os autores.

Ressaltamos como positivo o professor (B) perceber que o livro não contempla as variedades linguísticas da região, mostrando indícios de que, em algum momento de sua formação, houve contato com as teorias da variação, todavia aborda o fenômeno de forma imprecisa, tratando do assunto ainda de forma vaga.

Quanto ao processo de escolha, todos informaram que os livros eram avaliados e escolhidos em conjunto, com todos os professores da área de linguagens. Observamos que, ao avaliar o livro, os professores davam mais ênfase à distribuição das partes (literatura, gramática e produção de texto) do que, propriamente, aos conteúdos em si. Em nenhum momento, responderam que, durante o processo, avaliavam se os livros apresentavam conteúdos coerentes ou com desvios, conceitos corretos, ou mesmo se privilegiavam um conteúdo em detrimento de outro.

Os dados coletados indicam que o processo de escolha do livro ainda é muito superficial, com a ausência de critérios definidos para se verificar como o livro trata os conteúdos. Nota-se a ausência de uma base teórica que oriente e fundamente a escolha.

c) O livro didático ajuda na sua prática? Como?

Objetivamos, nesse tópico, verificar a autonomia do professor em relação ao livro didático e aos conteúdos apresentados. Nas respostas, todos os professores foram unânimes em afirmar que o livro didático é de extrema importância nas aulas de língua portuguesa, utilizado constantemente. O Professor(B) afirmou: "tenho consciência de que o livro é um subsídio, mas não é tudo; ele não vai dar aula".

Dentre os motivos elencados para o uso do livro, observamos: os professores gostam do livro; todos os alunos têm acesso ao livro; facilita a revisão dos conteúdos pelo aluno em casa; possui exemplos variados de gêneros textuais; sugere vídeos e documentários; possui variadas atividades. Constatamos, de fato, que o livro é o principal recurso didático utilizado em sala de aula, embora alguns tenham mencionado que o professor deve explorar outros recursos.

d) Como você caracteriza a fala dos alunos? O que você pensa deste modo de falar?

Os professores (A) e (C) responderam de formas muito semelhantes: a fala dos alunos é caracterizada pela idade, nível cultural, social e econômico e pelo lugar onde moram (serras, zona urbana, periferias). $\mathrm{O}$ professor (B) afirmou que utiliza a linguagem dos alunos a seu favor, pois a própria fala dos alunos demostra essa variedade que há na linguagem. Vejamos a fala de um dos professores entrevistados.

Professor (C):

[...] há um tempo atrás eu pensei que...as gírias, a linguagem dos alunos fosse uma dificuldade, né... que a... forma como eles utilizam a linguagem no whatsapp, no celular fosse uma dificuldade. Eu tinha esse pensamento, que, esse pensamento durou pouco tempo, porque eu tentei fazer com que isso se tornasse um atrativo pra eles, né?, mostrar, por exemplo, que quando você usa o "vc" ao invés de "você" não é errado, mas agente têm o momento de utilizar[...]

Em síntese, até aqui, os professores pesquisados reconhecem as diferenças que há na fala dos alunos e não as tratam com preconceitos ou com noções de "certo" ou "errado". De fato, é um avanço notório. Verificamos que procuram orientar os alunos quanto à diferença entre linguagem formal e informal (semelhantemente ao livro didático).

e) Você trabalha com textos de diferentes níveis de formalidades e dialetos? Por quê?

Com estas perguntas, buscamos verificar se os alunos tinham acesso a textos de diferentes gêneros, dos mais informais aos mais polidos linguisticamente, e sobre os dialetos que fazem parte da língua portuguesa. Constatamos, a seguir, alguns pontos positivos, como também respostas que ainda são fruto de uma abordagem superficial de variação. Vejamos o que afirmou o Professor (B):

\footnotetext{
Sim. Eu tento trabalhar. Geralmente, eu uso dos textos que estão nos livros, eu uso textos que eu extraio da internet, eu uso textos que extraio de revistas, de alguns livros que eu tenho. Por que que eu tento fazer isso? Para que o nosso aluno veja que a nossa linguagem ela não é limitada. Para que ele perceba que... existe dentro do universo da linguagem um universo de linguagens[...].
}

Um dos professores afirmou que durante a semana em que a entrevista foi realizada, estava trabalhando 
com as variedades linguísticas, mostrando as diferenças existentes entre as falas dos sulistas, mineiros, nordestinos e paulistas. Embora o trabalho seja positivo, verificamos novamente a tendência de trabalhar apenas o nível regional da variação.

f) Como você aborda a gramática em sala de aula?

As respostas desse tópico mostraram-nos concepções distintas acerca da abordagem de gramática em sala de aula. Um dos professores respondeu que, em face da dificuldade dos alunos em compreender o conteúdo no texto, optou por uma abordagem tradicional, com frases e enunciados isolados. Vejamos o exemplo:

Professor (B):

[...] Infelizmente, os nossos alunos têm bastante dificuldade em gramática, então o que é que eu faço? Eu pego aquele conteúdo gramatical e tento trazer para a realidade deles, eu construo enunciados a partir da vivência deles [...] se eu for trabalhar da maneira que está no texto, eles tem mais dificuldades, então eu sempre tento construir enunciados que têm a ver com eles.

Constata-se aqui que este posicionamento conservador ainda se encontra bastante enraizado.

g) Você trabalha com as noções de "certo" e "errado" em sala de aula? Por quê?

Quanto a esse questionamento, os professores foram unânimes em afirmar que não utilizam os conceitos de certo ou errado. Um dos professores afirmou que preferia utilizar as noções de "adequado" ou "inadequado" (professor (C). Porém, algumas respostas apresentavam contradições. Os dados analisados indicam que o fato de não utilizarem a nomenclatura "certo" ou "errado" não significa mudança na postura em sala de aula, apenas mudança da metalinguagem. Isso se evidencia no exemplo a seguir.

Professor (A):

Olha, a nossa maneira de trabalhar, a questão de trabalhar o certo e o errado, nós diferenciamos, evidenciamos o que que é norma-padrão... e o que que é norma popular. A questão de certo ou errado hoje não se diz: "há, você está falando errado" a gente trabalha muito com a questão de regionalismo, mas falando: a norma-padrão é essa! a norma culta é essa aqui! e é essa que deve ser escrita! até porque nós trabalhamos muito com as redações do ENEM.

Atentamos para a mudança da metalinguagem antiga, contudo o conceito permanece enraizado na prática. Observe-se, no exemplo mencionado, o termo "regionalismo", bastante utilizado pelos professores. Nesta resposta, pressupõe-se que o entendimento que o professor tem a respeito de variação linguística fica restrito apenas a questões de diferenças regionais, como em respostas anteriores. Os outros fenômenos em que ocorre a variação não são contemplados.

Por conseguinte, ao responder a este questionamento, o professor (A) põe em evidencia a dicotomia: variação regional $\mathrm{x}$ fala culta, conceitos, que, na verdade, estão colocados de forma equivocada.

h) Como os alunos encaram a fala dos professores?

Todas as respostas foram muito semelhantes para este tópico: os entrevistados afirmaram que há diferenças entre as falas; os alunos percebem essas diferenças; os professores muitas vezes tentam adequar a linguagem à fala dos alunos e os alunos estranham quando algum professor não segue as normas. Vejamos um exemplo:

Professor (A):

É engraçado essa...porque se o professor fala errado eles corrigem, eles zombam, eles podem falar errado, o professor não. E muitas vezes como ontem, foi-me feito a seguinte pergunta: tia, porque que os professores de português falam assim diferente? Eu disse: meu filho, você já imaginou como você me receberia, se eu, professora de português se quando eu chegasse aqui, eu dissesse: "bora, meu povo, pegui ai os seus cardernu, vamu fazer as atividades tudim" como você me caracterizaria?[...] Se errar pode ter certeza que eles vão comentar entre sí ,vão zombar. Isso é comum.

Ao final da entrevista, um dos professores deixa transparecer os conceitos ainda existentes em sua concepção de ensino. Ao focalizar a fala do professor (A), concluímos que os alunos agem com preconceitos quando os professores não monitoram a fala; do mesmo modo, o professor exterioriza resquícios de preconceito ao mencionar os conceitos de fala certa e fala errada.

Verificamos, com a aplicação do questionário, que os professores abordam as questões de variação linguística de maneira insuficiente, com imprecisões, recorrendo, muitas vezes, ao senso comum, embora tenhamos verificado algumas mudanças pontuais.

\section{CONSIDERAÇÕES FINAIS}

Neste artigo, buscamos averiguar e discutir as correlações existentes entre a concepção de variação linguística que orienta os professores da escola pesquisada e a que está presente no livro didático utilizado. Nosso objetivo era verificar como as teorias da Sociolinguística estão refletindo-se na prática dos professores e na produção dos livros didáticos destinados ao Ensino Médio.

De início, procuramos ver como a linguística moderna veio transformando-se, ao longo do tempo, desde os estruturalistas até o surgimento da abordagem da variação linguística, advinda da Sociolinguística. Refle- 
timos sobre como a utilização da abordagem sociolinguística em sala de aula pode ser útil no combate ao preconceito linguístico e na tarefa de ampliação da competência comunicativa do aluno, visto que proporciona liberdade para que o aluno possa se expressar em seu dialeto com segurança sem ser discriminado pelo professor ou pela classe.

Ao analisarmos o volume 2 da coleção Cereja; Magalhães (2013), verificamos que as seções de produção textual e análise linguística, embora possuam alguns avanços pontuais, em geral, continuam abordando o fenômeno de forma superficial, apresentando incoerências didáticas, conceitos equivocados, confundindo a norma culta com a norma-padrão; concebendo o fenômeno da variação apenas como a dicotomia linguagem formal e informal, sobretudo, privando o aluno de uma análise mais profunda sobre os fenômenos variáveis do português brasileiro.

$\mathrm{Na}$ análise das entrevistas, semelhantemente, verificamos que os professores pesquisados possuem conhecimentos insuficientes sobre a variação linguística, recorrendo ao senso comum, ao enfatizar o respeito às diferenças da linguagem, porém sem embasamento teórico necessário para trabalhar com as questões de preconceito linguístico e variedades linguísticas estigmatizadas. Por conseguinte, a concepção é tratada de forma rasa, detendo-se especificamente em questões de regionalismo.

Em síntese, os resultados apontam para a necessidade de maior embasamento teórico tanto nos livros didáticos, como na concepção dos professores, tendo em vista que esses últimos constituem peça fundamental no trabalho de reeducação sociolinguística em sala de aula. Nossa expectativa é que este trabalho possa ser útil às reflexões que apontam para a necessidade de um ensino que valorize a variedade linguística, não por modismo, ou superficialmente, mas visando unicamente ampliar as possibilidades linguísticas dos alunos e banir os preconceitos ainda existentes na sociedade brasileira hodierna quanto à variação linguística, sobretudo na escola.
BAGNO, M. Nada na língua é por acaso: por uma pedagogia da variação linguística. 1. ed. São Paulo: Parábola editorial, 2007.

\section{Gramática pedagógica do português}

brasileiro. 1. ed. São Paulo: Parábola Editorial, 2011.

BORTONI-RICARDO, S. M. Educação em língua materna: a sociolinguística em sala de aula. 1. ed. São Paulo: Parábola Editorial, 2004.

Nós cheguemu na escola, e agora?

Sociolinguística e educação. 2. ed. São Paulo: Parábola Editorial, 2005.

BRASIL, S. d. E. B. Parâmetros curriculares nacionais para o ensino médio: Parte II linguagens, códigos e suas tecnologias. 1 . ed. Brasília: MEC/SEB, 2000.

CALVET, L.-J. Sociolinguística: uma introdução crítica. 1. ed. São Paulo: Parábola, 2002.

CARVALHO, C. d. Para compreender Saussure. 5. ed. Rio de Janeiro: Presença Edições, 1987.

CEREJA, W. R.; MAGAlHãES, T. C. Português: linguagens. 1. ed. São Paulo: Saraiva, 2013. v. 2.

FARACO, C. A. Norma Culta Brasileira: desatando alguns nós. São Paulo. 1. ed. São Paulo: Parábola Editorial, 2008.

LABOV, W. Padrões sociolinguísticos. 1. ed. São Paulo: Parábola, 2008.

RAQUEL, B. M. G. Sociolinguística, política educacional e a escola pública estadual de Fortaleza/CE: correlações teórico-metodológicas e político-pedagógicas. Dissertação (Mestrado em Linguística) - Universidade Federal do Ceará, Fortaleza, 2007. 180f.

\section{REFERÊNCIAS}

ALKMIM, T. M. Sociolinguística (parte i). In: MUSSALIM, F.; BENTES, A. C. (Ed.). Introdução à linguística: domínios e fronteiras. 9. ed. São Paulo: Cortez, 2012.

ANTUNES, I. Aula de Português: encontro e interação. 1. ed. São Paulo: Parábola editorial, 2003. 